\title{
Spectrophotometric Study for the Reaction of Pentoxifylline Hydrochloride with 1,2-Naphthoquinone-4-Sulphonate: Kinetics, Mechanism and Application for Development of High-Throughput Kinetic Microwell Assay for Pentoxifylline in Quality Control Laboratory
}

\author{
Ashraf M. Mahmoud1,2*, Saad A. AlQahtani ${ }^{3}$ \\ ${ }^{1}$ Department of Pharmaceutical Analytical Chemistry, Faculty of Pharmacy, Assiut University, Assiut, Egypt \\ ${ }^{2}$ Department of Pharmaceutical Chemistry, College of Pharmacy, Najran University, Najran, Kingdom of \\ Saudi Arabia \\ ${ }^{3}$ Department of Clinical Pharmacy, College of Pharmacy, Najran University, Najran, Kingdom of Saudi Arabia \\ Email: *a.mahmoud2007@yahoo.com
}

Received 17 December 2015; accepted 30 January 2016; published 2 February 2016

Copyright (C) 2016 by authors and Scientific Research Publishing Inc.

This work is licensed under the Creative Commons Attribution International License (CC BY). http://creativecommons.org/licenses/by/4.0/

(c) (i)

\section{Abstract}

Spectrophotometric study was carried out, for the first time, to investigate the reaction between the vasodilator pentoxifylline hydrochloride (POX) and 1,2-naphthoquinone-4-sulphonate (NQS) reagent. The reaction occurs in alkaline medium to activate the nucleophilic substitution reaction producing an orange-colored product measured spectrophometrically at $\lambda_{\max } 472 \mathrm{~nm}$. The variables affecting the reaction were carefully studied and the conditions were optimized. The kinetics of the reaction was investigated and its activation energy was found to be $0.262 \mathrm{cal} / \mathrm{mol}$. Owing to its low activation energy, the reaction proceeded easily and was successfully used for simple and rapid assay of POX. The stoichiometry of the reaction was determined (1:1), and the reaction mechanism was suggested. To develop a high-throughput methodology used in quality control laboratory, a comparative study of the reaction using the conventional spectrophotometric versus microwell assay was applied. Under the optimum reaction conditions, the initial rate

\footnotetext{
${ }^{*}$ Corresponding author.
}

How to cite this paper: Mahmoud, A.M. and AlQahtani, S.A. (2016) Spectrophotometric Study for the Reaction of Pentoxifylline Hydrochloride with 1,2-Naphthoquinone-4-Sulphonate: Kinetics, Mechanism and Application for Development of High-Throughput Kinetic Microwell Assay for Pentoxifylline in Quality Control Laboratory. American Journal of Analytical Chemistry, 7, 179-191. http://dx.doi.org/10.4236/ajac.2016.72015 
and fixed time methods were utilized for constructing the calibration graphs for determination of POX concentrations. The linear range was $10-120 \mu \mathrm{g} / \mathrm{ml}$ with good correlation coefficients (0.9987 - 0.9998). The LOD was 2.5 and $3.4 \mu \mathrm{g} / \mathrm{ml}$ for initial rate and fixed time methods, respectively. The intra- and inter-day accuracy and precision of the developed methods were satisfactory, where RSD was $\leq 3.94 \%$. The present methods have been successfully applied to the determination of POX in its pharmaceutical tablets, and the percentage recovery values were $97.9 \%-101.9 \%$. Therefore, we strongly recommend the proposed methods for determination of POX in quality control laboratories.

\section{Keywords}

Pentoxifylline HCl, 1,2-Naphthoquinone-4-Sulphonate, Kinetic Spectrophotometry, Pharmaceutical Analysis, Micro-Well Plate Reader

\section{Introduction}

Pentoxifylline hydrochloride (POX); 3,7-dihydro-3,7-dimethyl-1-(5-oxohexyl)-1H-purine-2,6-dione is the first clinically effective drug approved for the treatment of intermittent claudication secondary to chronic occlusive vascular disease [1]. It was used for treatment of Reynould's syndromes and transient ischemic attacks, too. Moreover, it can also be used as a vasodilator to lower the blood pressure in treatment of peripheral vascular disorders [1] [2]. Recently, POX has wide clinical applications in dermatology because it has a variety of physiological effects at the cellular level, which may be very important in treating a diverse group of diseases as psoriasis. In most cutaneous diseases, POX was regarded as a valuable therapeutic adjuvant. POX may best serve as a corticosteroid-sparing agent in dermatology [3]. Because of the therapeutic importance and clinical success of POX, it has been widely used throughout many countries worldwide [3].

Numerous analytical methods have been developed for the quantitative determination of POX in pure, pharmaceutical dosage forms and/or biological fluids. The methods published prior to 1998 have been reviewed by Indrayanto G et al. [2]. The reported methods after 1998 include spectrophotometry [4] [5], fluorimetry [6], high-performance liquid chromatography [7]-[13], thin layer chromatography [13], Gas chromatography [14], and electrochemistry [15]. Despite of the higher sensitivity and selectivity of the separation-based methods, the instrumentation and high analysis cost limited their use in quality control laboratories. Spectrophotometry is the most convenient and widely available analytical technique due to its inherent simplicity and low cost. Kinetic spectrophotometry has been becoming of great interest in pharmaceutical analysis of drug content [16] owing to its improved selectivity. The application of microwell plates as reaction vessels instead of the calibrated flasks and classical cuvettes in the pharmaceutical analysis of drug content is becoming of great interest and broadened to the dissolution studies where higher limits of quantification are not required [17] [18]. This application can increase the automation and high-throughput property as well as decreasing the cost of the analysis to become more suitable for the determination of drug substance in quality control laboratories [19] [20]. 1,2-naphthoquinone-4-sulphonate (NQS) has been used for the determination of many pharmaceuticals [21]-[24]. The substitution reaction between NQS and POX has not been investigated, yet. For these reasons, the present work was devoted to explore NQS in the development of a high-throughput microwell assay, for the first time, for the determination of POX in its pharmaceutical tablets. To develop an automated high-throughput methodology used in quality control laboratory, a comparative study for the reaction using the conventional spectrophotometry versus microwell assay was made.

\section{Experimental}

\subsection{Instrumentation}

Multi-Detection Microplate Reader (BioTek Synergy 2, BioTek Instruments Inc., USA) was used for all measurements in 96-microwell plates. A Shimadzu model UV-1601 PC (Kyoto, Japan) UV-VIS double beam spectrophotometer with matched 1-cm quartz cells was used for recording the absorption spectrum. Polypropylene microplates, 96 well with U bottom were obtained from Santa Cruz Biotechnology, Inc. (USA). Finn pipette 
adjustable 8 channel-pipettes were purchased from Sigma Chemical Co., USA.

\subsection{Chemicals, Reagents and Pharmaceutical Formulations}

Pentoxifylline hydrochloride (POX), (Servier Egypt Industries Limited, Egypt). 1,2-Naphthoquinone-4-sulpho-nic acid (NQS) sodium salt (Aldrich Chemical Co., Milwaukee, USA) was $5 \times 10^{-2} \mathrm{M}$ aqueous solution. Sodium hydroxide solution was $0.25 \mathrm{M}$ aqueous solution. Trental ${ }^{\circledR}$ (Servier Egypt Industries Ltd., Egypt), Vasotal ${ }^{\circledR}$ (T3A, Egypt), and Pexal ${ }^{\circledR}$ (Mepha, Egypt) tablets are labeled to contain $400 \mathrm{mg}$ of pentoxifylline hydrochloride per tablet. All solvents and other chemicals used throughout this study were of analytical grade.

\subsection{Preparation of Standard Solutions}

An accurately weighed amount $(60 \mathrm{mg}$ ) of POX was quantitatively transferred into a 50-ml calibrated flask, dissolved in $30 \mathrm{ml}$ distilled water, completed to volume with distilled water to produce a stock solution of 1.2 $\mathrm{mg} / \mathrm{ml}$. This stock solution was then diluted with distilled water to obtain working standard solutions of 100 $1200 \mu \mathrm{g} / \mathrm{ml}$.

\subsection{Preparation of Sample Solution of Pharmaceutical Tablets}

Twenty tablets of each formulation were weighed and finely powdered. A quantity of the mixed powder equivalent to $40 \mathrm{mg}$ of POX was transferred into a 50-ml calibrated flask and dissolved in $25 \mathrm{ml}$ distilled water. The contents of the flask were swirled, sonicated for $5 \mathrm{~min}$, and then completed to the mark with distilled water. The contents were mixed well, filtered, and the first portion of the filtrate was rejected. The filtrate solution yield working solutions of $800 \mu \mathrm{g} / \mathrm{ml}$ for analysis.

\subsection{General Recommended Procedures}

\subsubsection{Using the Conventional Spectrophotometry}

Accurately measured aliquots of POX solution containing $100-1200 \mu \mathrm{g} / \mathrm{ml}$ were transferred into separate 10-ml calibrated flasks. Two milliliters of sodium hydroxide solution $(0.25 \mathrm{M})$ was added followed by $2 \mathrm{ml}$ of NQS solution $\left(5 \times 10^{-2} \mathrm{M}\right)$. The solution was diluted to volume with distilled water and mixed well. After mixing, the reaction mixture was immediately transferred to a spectrophotometric cell and the absorbance was recorded as a function of time at room temperature $\left(25^{\circ} \mathrm{C} \pm 2^{\circ} \mathrm{C}\right)$ for $10 \mathrm{~min}$ at $472 \mathrm{~nm}$ against reagent blank treated similarly.

\subsubsection{Using the Microwell Plate Format}

Hundred microliters of the standard or sample POX solution of OMZ $(100-1200 \mu \mathrm{g} / \mathrm{ml})$ was transferred into the wells of 96-microwell plate. Fifty microliters of sodium hydroxide solution $(0.25 \mathrm{M})$ followed by $50 \mu \mathrm{l}$ of NQS solution $\left(5 \times 10^{-2} \mathrm{M}\right)$ were added to each well. The absorbance intensities of the resulting solutions were recorded as a function of time at room temperature $\left(25^{\circ} \mathrm{C} \pm 2^{\circ} \mathrm{C}\right)$ for $10 \mathrm{~min}$. The measurements were made using optical filter $475 \mathrm{~nm}$ and multi-detection microplate reader. Blank wells were treated similarly using $100 \mu 1$ of distilled water instead of POX. The absorbance intensities of the blank wells were subtracted from those of standard or sample wells.

\subsection{Determination of the Reaction Stoichiometry}

The Job's method of continuous variation [25] was employed for determination of the stoichiometry of the reaction between POX and NQS. Master equimolar $\left(3.6 \times 10^{-4} \mathrm{M}\right)$ aqueous solutions of POX and NQS were prepared. Series of $5 \mathrm{ml}$ portions of the master solutions of POX and NQS were made up comprising different complementary proportions (0:10, 1:9.. 9:1, 10:0, inclusive) in 10.0 ml-calibrated flasks. Two milliliters of $0.25 \mathrm{M}$ $\mathrm{NaOH}$ was added to each flask, and the solutions were diluted to volume with distilled water and mixed well. The absorbance of the solutions was measured after $10 \mathrm{~min}$ at $472 \mathrm{~nm}$ against reagent blank treated similarly.

\subsection{Data Acquisition and Processing}

The kinetic data recorded for the designed methods was transformed to the Microsoft Office Excel software, 
version 2010, for curve fitting, regression analysis, and statistical calculations. In the initial rate method of analysis, the initial rate $(V)$ of the reaction was obtained from the slope of the absorbance-time curve at definite concentration. The calibration curve was constructed by plotting (log $V$ ) at different concentrations versus (log $C$ ) of POX. Alternatively, the fixed time method was used for constructing the calibration curve by plotting the absorbance measured after fixed time of $10 \mathrm{~min}$ vs. the corresponding POX concentrations. The least squares method was used for getting the regression equation.

\subsection{Validation of the Proposed Kinetic Methods}

The following validation parameters were assessed and evaluated according to ICH guidelines [26]. The standard curve for determination of POX was constructed applying the general assay procedure using either the initial rate or fixed time method. After getting the regression equation, the limit of detection (LOD) and limit of quantitation (LOQ) were determined [26] using the formula: LOD or LOQ $=\kappa S D_{a} / b$, where $\kappa=3.3$ for LOD and 10 for LOQ, $S D_{a}$ is the standard deviation of the intercept, and b is the slope (sensitivity) of the proposed method. Intra- and inter-day accuracy and precision of the proposed methods were assessed by recovery studies at three (low, medium and high) concentration levels. Recovery was determined by the standard addition method. Known amounts of POX were added to the pre-determined drug-containing dosage forms, and then determined by the proposed methods. The mean recovery was determined by dividing the measured concentrations to the concentrations taken for analysis, expressed in percentages. The intra-day precision and accuracy were determined by carrying out the assay of six replicate samples of each concentration as one batch in a single run, while the inter-day precision and accuracy were determined by repeating the assays for the same samples at three different days. The selectivity of the proposed method was studied by testing the interferences liability from the excipients of the dosage forms. Common excipients such as starch, glucose, lactose, acacia, and magnesium stearate were used in this study. The recovery was calculated each time. Ruggedness was also tested by two different analysts at two different elapsed times. Moreover, robustness was evaluated at small variation in the reagents' concentrations, reaction temperature and reaction time

\section{Results and Discussion}

\subsection{Involved Reaction, Design and Strategy of the Assay Development}

1,2-Naphthoquinone-4-sulphonate (Folin's reagent) is frequently used as an analytical reagent for the determination of nucleophilic analytes in weak alkaline medium at normal or slightly elevated temperature. It has been used for the determination of primary amines [21]-[23], secondary amines [24], thiols [27] and active methylene containing compounds [28] [29] by spectrophotometry [21], [23] [24] and spectrofluorometry [22], [27] after the reduction of the condensation product to the fluorescent 1,2-dihydroxynaphthalene-4-derivative. In the present work, POX was found to react with NQS producing an orange-colored product measured at $\lambda_{\max } 472 \mathrm{~nm}$. Figure 1 shows the absorption spectrum of the reaction product of POX with alkaline NQS. The preliminary investigation of the reaction showed that the absorbance of the colored product increased with time to the maximum, then rapidly decreased without a stable period for the measurements. This finding attracted our notice to develop an automated kinetic spectrophotometric assay for the determination of POX to overcome this disadvantage. This can be done by carrying out the reaction in 96-microwell plate as a reaction vessel and measuring the signal with a microplate reader depending on our previous experience [19] [20]. In order to come to this conclusion, the reaction was investigated under various conditions of reagent concentration and alkalinity as well as reaction time and temperature. The following sections describe the conditions under which the reaction of POX with alkaline NQS fulfills the requirements necessary for its spectrophotometric analysis.

\subsection{Optimization of the Reaction Conditions}

In order to investigate the effect of NQS concentration on the reaction product, different concentrations (1.0 - 10 $\times 10^{-2} \mathrm{M}$ ) of NQS working solution were tested. The results revealed that the absorbance and the initial reaction rate increased with increasing the concentration of NQS and maximum values were attained when the NQS concentration reached $5 \times 10^{-3} \mathrm{M}$ in the final solution $\left(5 \times 10^{-2} \mathrm{M}\right.$ working solution) as shown in Figure 2 . Also, different volumes $(0.5-4.0 \mathrm{ml})$ from NQS working solution $\left(5 \times 10^{-2} \mathrm{M}\right)$ were tested. The results indicated that $2 \mathrm{ml}$ of $5 \times 10^{-2} \mathrm{M}$ NQS working solution yielded the highest values. Therefore further testing was performed 


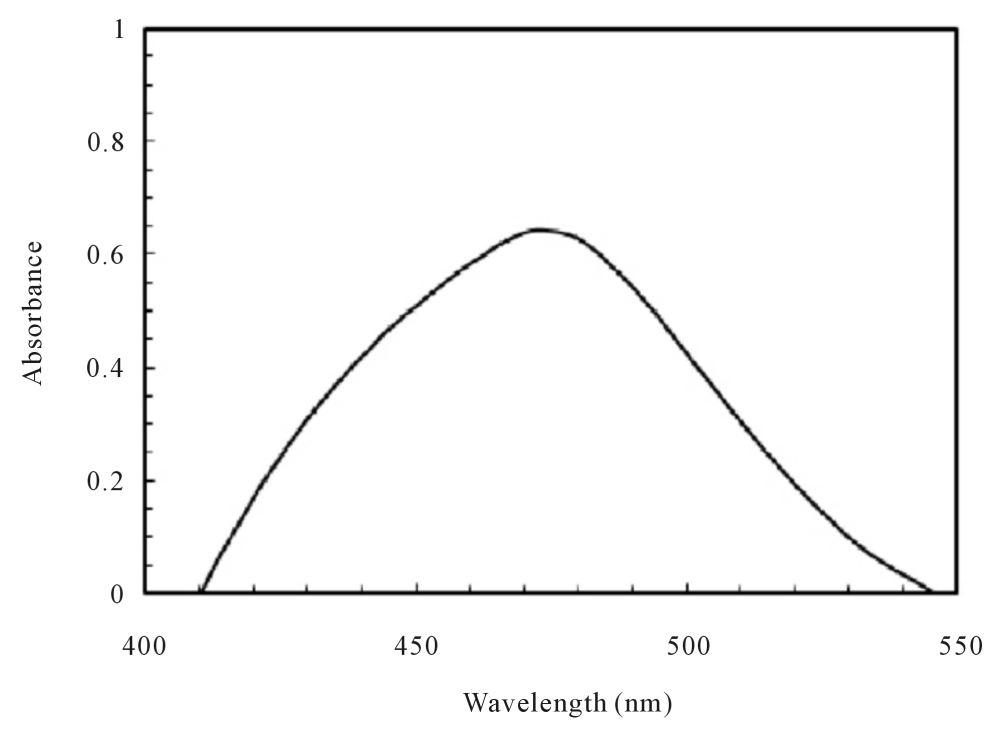

Figure 1. Absorption spectrum of the reaction product of POX $(80 \mu \mathrm{g} / \mathrm{ml})$ with NQS reagent $(0.005 \mathrm{M})$ in alkaline medium $(0.05 \mathrm{M} \mathrm{NaOH})$ at room temperature.

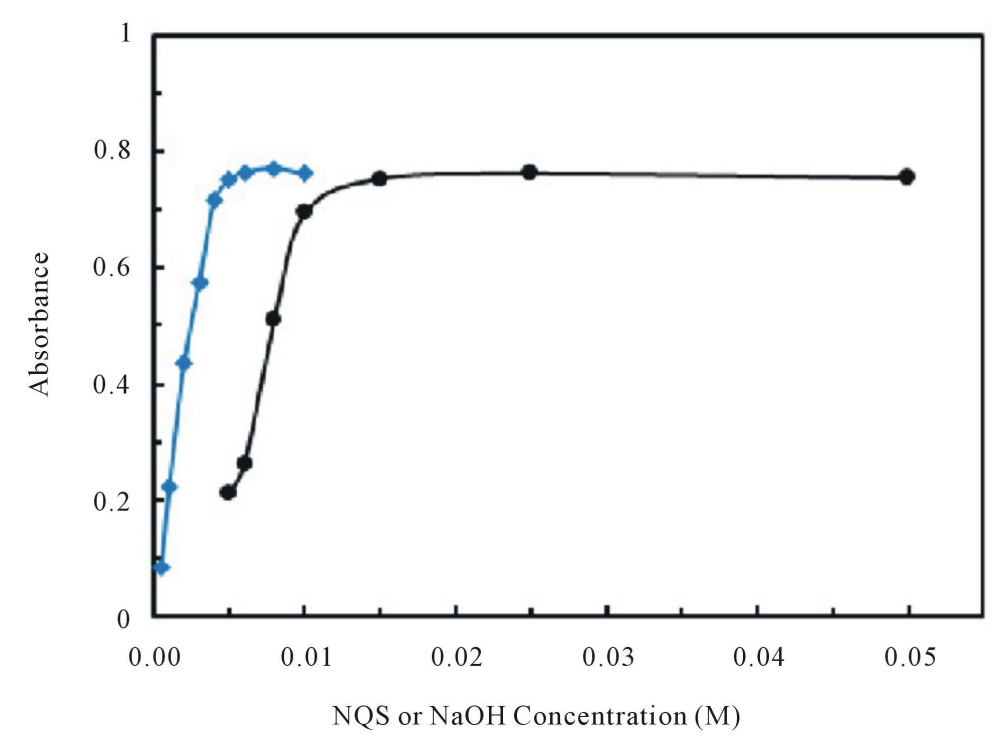

Figure 2. Effect of molar concentrations of both NQS reagent $(\bullet)$ and $\mathrm{NaOH}$ (O) on the absorption intensity of the reaction product of POX $(80 \mu \mathrm{g} / \mathrm{ml})$ with NQS.

using $2 \mathrm{ml}$ of $5 \times 10^{-2} \mathrm{M}$ solution of NQS using the conventional spectrophotometry. Using the microwell plate format, the results indicated that $50 \mu \mathrm{l}$ of $5 \times 10^{-2} \mathrm{M}$ NQS solution in total volume of $200 \mu \mathrm{l}$ (plate well volume) resulted in the highest absorbance values.

To investigate the effect of sodium hydroxide concentration on the initial reaction rate, different concentrations $(0.01-1.0 \mathrm{M})$ of $\mathrm{NaOH}$ solution were tested. The results showed that maximum absorbance was obtained when $\mathrm{NaOH}$ concentration of $0.025 \mathrm{M}$ in the final solution was used $(0.25 \mathrm{M}$ working solution) (Figure 2). Furthermore, different volumes $(1.0-5.0 \mathrm{ml})$ from $0.25 \mathrm{M}$ working solution were investigated and indicated that 2 $\mathrm{ml}$ of $0.25 \mathrm{M} \mathrm{NaOH}$ solution in total volume of $10 \mathrm{ml}$ was the ideal concentration. Using the microwell plate format, the results indicated that $50 \mu \mathrm{l}$ of $0.25 \mathrm{M} \mathrm{NaOH}$ solution in total volume of $200 \mu$ l gave the highest absorbance values. 
Because the formation of the colored product increases with time, we had to optimize the time of the reaction between POX and NQS by monitoring the reaction at different times $(0.2,2.5,5,7.5,10,12.5,15,17.5,20,25$, $30 \mathrm{~min}$ ). Figure 3 showed that the highest absorbance values were obtained after $10 \mathrm{~min}$ followed by gradual decrease in the absorbance after $12 \mathrm{~min}$. This is a strong disadvantage if we use the conventional spectrophotometry. However, we can overcome this disadvantage by using either the microwell plate format or the kinetic initial rate method for the analysis.

In spite of heating the reaction mixture in the range of $25^{\circ} \mathrm{C}-50^{\circ} \mathrm{C}$ had slight positive effect on the reaction, however to simplify the procedure, further testing was performed at room temperature $\left(25^{\circ} \mathrm{C} \pm 2^{\circ} \mathrm{C}\right)$. The solvents used for NQS reagent as well as for dilution of the reaction mixture were carefully studied using different solvents: water, methanol, ethanol, isopropanol, and acetonitrile. Water was found to be the optimum solvent as the highest absorbance values were obtained. Table 1 shows the optimum conditions for the reaction between POX and NQS using both the conventional and 96-microwell spectrophotometric methods.

\subsection{Stoichiometry and Reaction Mechanism}

The stoichiometry of the reaction of POX with NQS was determined by the Job's method of continuous variation [25]. The POX: NQS ratio was found to be 1:1. The POX molecule contains four tertiary amino groups and only one active methylene group. The tertiary amino groups cannot react with NQS, however, the active methylene group can react with alkaline NQS. Therefore, the mechanism of POX-NQS reaction was suggested to proceed according to the pathway given in Figure 4.

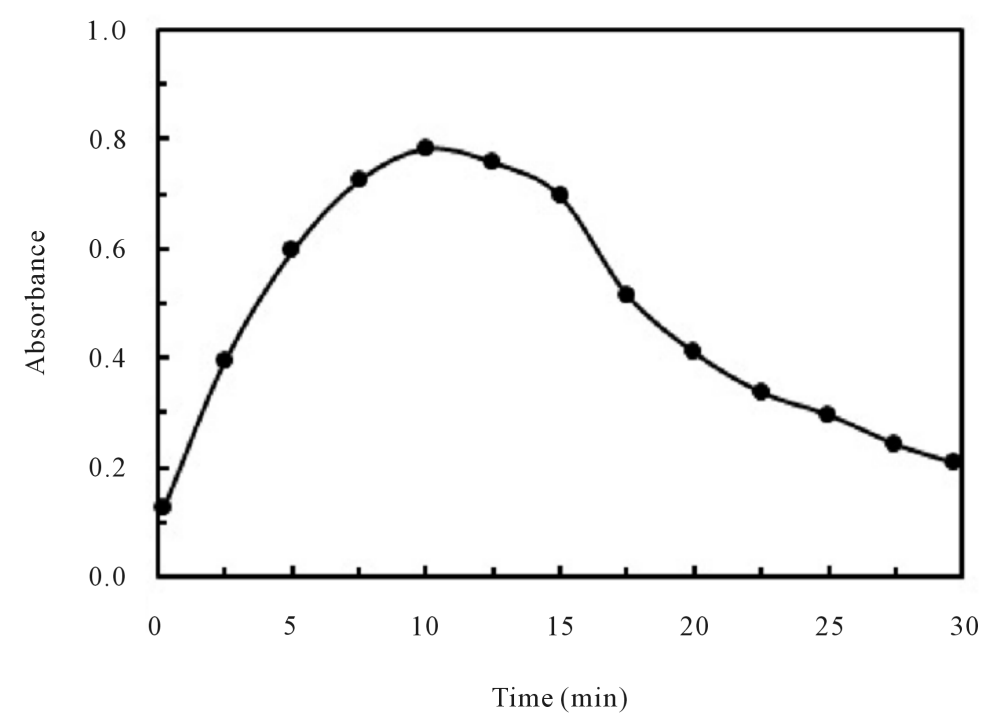

Figure 3. Effect of time on the absorption intensity of the reaction product of POX $(90 \mu \mathrm{g} / \mathrm{ml})$ with NQS $(0.005 \mathrm{M})$ in alkaline medium $(0.05 \mathrm{M} \mathrm{NaOH})$ at room temperature.

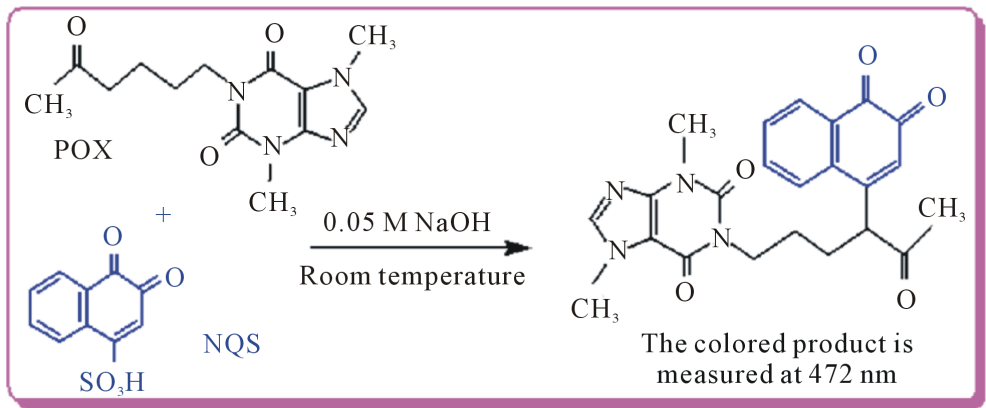

Figure 4. The proposed pathway for the reaction of POX with alkaline NQS. 
Table 1. Optimum conditions for the substitution reaction of POX with NQS.

\begin{tabular}{ccc}
\hline Conditions & Conventional spectrophotometric method & Microplate method \\
\hline NQS working conc. $(\mathrm{M})$ & 0.05 & 0.05 \\
NQS volume $(\mu \mathrm{l})$ & 2000 & 50 \\
NaOH working conc. $(\mathrm{M})$ & 0.25 & 0.25 \\
$\mathrm{NaOH}$ volume $(\mu \mathrm{l})$ & 2000 & 50 \\
Reaction time (min) & 10 & $25 \pm 2$ \\
Temperature $\left({ }^{\circ} \mathrm{C}\right)$ & $25 \pm 2$ & Dist. water \\
Solvent & Dist. water & 200 \\
Total volume of final solution $\mu \mathrm{l})$ & 10,000 & Microplate reader \\
Measuring instrument & UV-VIS Spectrophotometer & 475 \\
\hline
\end{tabular}

\subsection{Kinetics of the Investigated Reaction}

\subsubsection{Order of the Reaction}

Under the described optimum conditions (Table 1), the absorbance-time plots for the reaction of POX with alkaline NQS reagent was constructed (Figure 5). The initial rates of the reaction were determined from the slopes tangents of the absorption-time curves. The order of the reaction with respect to NQS was determined by investigating the reaction at different NQS concentrations keeping the concentration of POX constant. The plot of the initial rate, against NQS concentrations was linear with a slope value of 1.007 indicating that the reaction is a first order with respect to NQS. The plot of the initial rate, against POX concentrations (keeping the reagents concentrations constant) was linear with a slope value of 0.953 describing a first order rate with respect to POX, too. However under the optimized experimental conditions, the concentration of POX was determined using relative excess amounts of the analytical and other conditional reagents. Therefore, pseudo-first order conditions were obtained with respect to POX and the reaction rate was found to obey the Equation (1) [30]:

$$
\log V=\log \Delta A / \Delta t=\log K^{\prime}+n \log C
$$

where: $V$ is the initial reaction rate, $A$ is the absorbance intensity, $t$ is the measuring time, $K^{\prime}$ is the pseudo-first order rate constant, $C$ is the molar concentration of POX, and $n$ (slope) is the order of the reaction. The results showed a linear plot with good correlation coefficient $(r)$ equal 0.9977 and slope $(n)$ equal $0.95(\approx 1)$ which proved that the order of the investigated reaction was first order.

\subsubsection{Activation Energy and the Standard Free Energy Change of the Product}

The activation energy of the reaction under investigation can be determined from the logarithmic form of Arrhenius equation [31]:

$$
\log k=\log A-E a / 2.303 R T
$$

where: $k$ is the rate, $A$ is a constant known as Arrhenius frequency factor, Ea is the activation energy, $T$ is the absolute temperature $\left(273+{ }^{\circ} \mathrm{C}\right)$, and $\mathrm{R}$ is the gas constant $\left(1.987 \mathrm{cal} / \mathrm{mol}{ }^{\circ} \mathrm{C}\right)$.

The activation energy was determined by measuring the absorbance of the reaction product at different temperatures; $25^{\circ} \mathrm{C}, 30^{\circ} \mathrm{C}, 35^{\circ} \mathrm{C}, 40^{\circ} \mathrm{C}$, and $50^{\circ} \mathrm{C}$ keeping the concentrations of POX, NQS and $\mathrm{NaOH}$ constant. The absorbance-time plot at these temperatures were constructed to determine the rates, then plotting log rates $(k)$ vs $1 / \mathrm{T}$ to determine the slope $(-\mathrm{Ea} / 2.303 \mathrm{R})$ of the line as shown in Figure 6. The value of the slope was -0.0573 and the activation energy of the investigated product was $0.262 \mathrm{cal} / \mathrm{mol}$. The positive sign of the activation energy indicated that the product formation increased with increasing the temperature, however, its very small value indicated the slight positive effect of heating the reaction mixture.

The standard free energy change of the reaction product was determined using the equation III [31], and its value was $-2.903 \mathrm{Kcal} / \mathrm{mol}$. The Negative sign of $\Delta G^{\circ}$ indicates endothermic condensation reaction. 


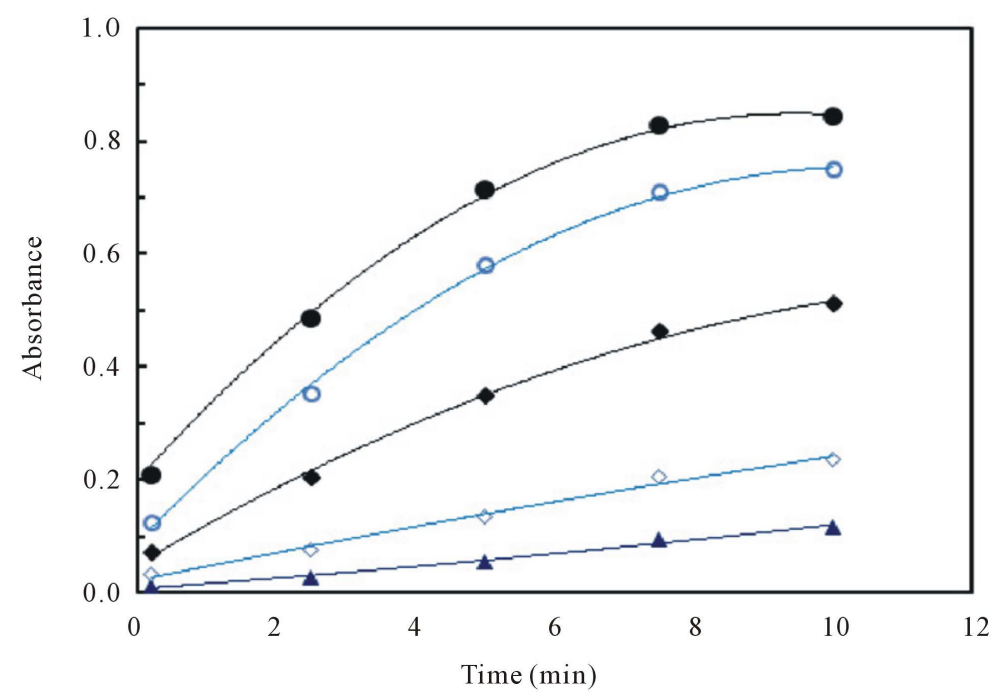

Figure 5. Absorbance-time curve for the reaction of POX with NQS (0.005 M) in alkaline medium $(0.05 \mathrm{M} \mathrm{NaOH})$ at room temperature. The molar concentrations of POX were $0.54 \times 10^{-4}(\boldsymbol{\Delta}), 1.08 \times 10^{-4}(\diamond), 2.16 \times 10^{-4}(\diamond), 3.24$ $\times 10^{-4}(\mathrm{O})$, and $3.6 \times 10^{-4} \mathrm{M}(\mathbf{O})$.

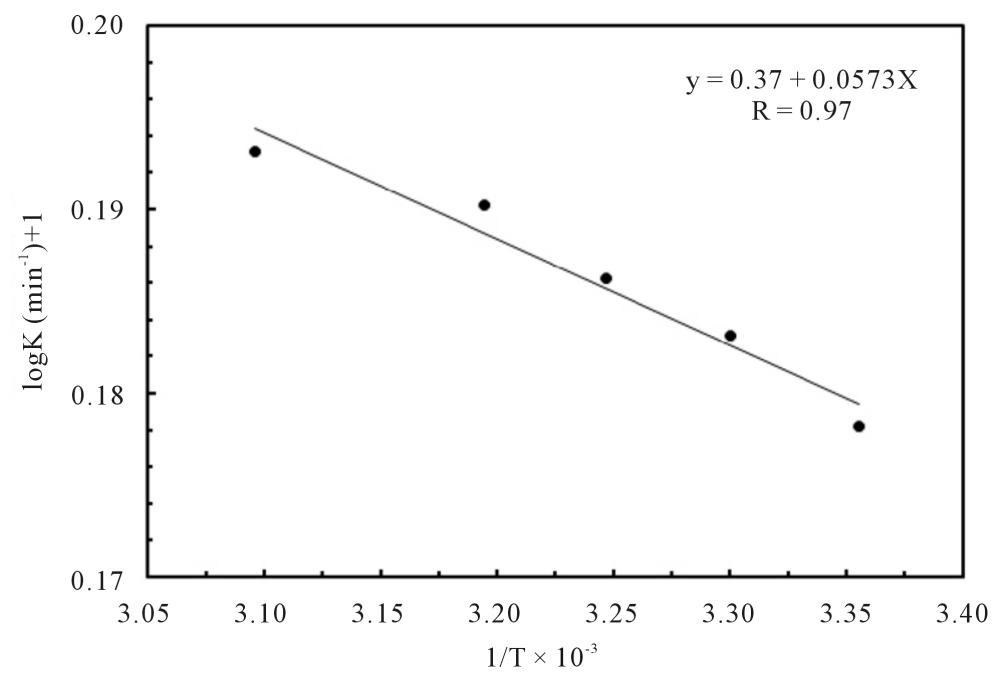

Figure 6. Arrhenius plot for the activation energy of the reaction of POX (90 $\mu \mathrm{g} / \mathrm{ml})$ with NQS reagent $(0.005 \mathrm{M})$ in alkaline medium $(0.05 \mathrm{M} \mathrm{NaOH})$ at different reaction temperatures $\left(25^{\circ} \mathrm{C}, 30^{\circ} \mathrm{C}, 35^{\circ} \mathrm{C}, 40^{\circ} \mathrm{C}\right.$, and $\left.50^{\circ} \mathrm{C}\right)$. " 1 " was added to the values of $\log \mathrm{K}$ to eliminate the negative sign of the values.

$$
\Delta G^{0}=-2.303 R T \log K
$$

\subsection{Validation of the Proposed Methods}

Using the general assay procedures (Table 1), the following validation parameters were assessed and evaluated according to ICH guidelines [26].

\subsubsection{Linearity, Limits of Detection and Quantitation}

\section{1) Initial Rate Method}

The quantitation depending on initial rates of the POX reaction would follow a pseudo-first order Equation 
(1). Regression analysis using the method of least square resulted in the equation $(\log V=2.129+0.953 \log C)$ with good correlation coefficient (0.998). The linear range was $0.4 \times 10^{-4}-4.31 \times 10^{-4} \mathrm{M}(10-120 \mu \mathrm{g} / \mathrm{ml})$ with a limit of detection (LOD) and limit of quantitation of 2.51 and $7.59 \mu \mathrm{g} / \mathrm{ml}$, respectively. These values confirmed the suitability of the method for determination of POX in quality control laboratory.

\section{2) Fixed Time Method}

In this method, the absorbance of the reaction product for each POX concentration was measured at a preselected fixed time. Standard curve of absorbance vs. corresponding POX concentrations was established after 10 min. Regression equation $(A=0.0085 X-0.0124)$ with linear range $(10-120 \mu \mathrm{g} / \mathrm{ml})$ and good correlation coefficients (0.9997) was obtained. The LOD and LOQ were 3.4 and $10.2 \mu \mathrm{g} / \mathrm{ml}$, respectively (Table 2).

\subsubsection{Accuracy and Precision}

Intra- and inter-day accuracy and precision of the designed methodology were assessed [32] by recovery studies at three concentration levels $(15,60$ and $100 \mu \mathrm{g} / \mathrm{ml})$. Table 3 shows the values of the intra- and inter-day precision (determined as \% RSD) and accuracy (determined as \% recovery) of the proposed conventional and microwell spectrophotometric methods using both initial rate and fixed time. This high level of precision and accuracy indicated the suitability of the designed methodology for the analysis of POX in quality control laboratory. For comparative evaluation and/or recommendations of these methods depending on the precision level, the designed microwell assay might be highly recommended for routine analysis of POX in quality control laboratories.

\subsubsection{Selectivity of the Proposed Methodology}

The designed methods have the advantage of that all measurements are performed in the visible region at 472 $\mathrm{nm}$, away from the near UV absorbing interfering excipients that might be co-extracted from POX-containing dosage forms. The potential interferences from the excipients were investigated. Samples were prepared by mixing known amount $(20 \mathrm{mg}$ ) of POX with various amounts of the common excipients such as starch, glucose, lactose, acacia, and magnesium stearate. The results (Table 4) revealed that no interference was observed from any of these excipients with the designed methods, where the average recovery results was $101.41 \% \pm 1.69 \%$.

\subsubsection{Ruggedness and Robustness}

The ruggedness was tested by applying the designed kinetic methods to the assay of POX using the same optimum conditions but using two different analysts and different elapsed time. Results obtained were reproducible as RSD did not exceed 3\%.

Robustness of the designed procedure was examined by evaluating the influence of small variation in the

Table 2. Quantitative and kinetic parameters for the analytical performance of the designed microwell spectrophotometric method after fixed time of $10 \mathrm{~min}$.

\begin{tabular}{cc} 
Parameter & Value \\
Linear range $\left(\mu \mathrm{g} \cdot \mathrm{ml}^{-1}\right)$ & $10-120$ \\
Intercept & -0.0124 \\
Standard deviation of the intercept & 0.0086 \\
Slope & 0.0085 \\
Correlation coefficient $(\mathrm{r})$ & 0.9997 \\
Limit of detection, $\mathrm{LOD}\left(\mu \mathrm{g} \cdot \mathrm{ml}^{-1}\right)$ & 3.4 \\
Limit of quantification, $\mathrm{LOQ}\left(\mu \mathrm{g} \cdot \mathrm{ml}^{-1}\right)$ & 10.2 \\
Order of the reaction $(\mathrm{n})$ & $0.96(\sim 1.0)$ \\
The activation energy, $\mathrm{Ea}\left(\mathrm{cal}^{-1} \cdot \mathrm{mol}^{-1}\right)$ & 0.262 \\
The standard free energy change, $\Delta \mathrm{G}^{\circ}\left(\mathrm{Kcal}^{-1} \mathrm{~mol}^{-1}\right)$ & -2.903 \\
Molar absorptivity, $\varepsilon\left(\mathrm{l} \mathrm{mol}{ }^{-1} \cdot \mathrm{cm}^{-1}\right)$ & $2.37 \times 10^{3}$ \\
\hline
\end{tabular}


Table 3. Evaluation of the intra- and inter-day accuracy and precision of the initial rate and fixed time methods of the designed methodology for determination of POX.

\begin{tabular}{|c|c|c|c|}
\hline \multirow{2}{*}{ Spectrophotometric method } & \multirow{2}{*}{ Amount taken $\left(\mu \mathrm{g} \cdot \mathrm{ml}^{-1}\right)$} & \multicolumn{2}{|c|}{ Recovery $(\% \pm \mathrm{RSD})^{\mathrm{a}}$} \\
\hline & & Initial rate method & Fixed time method \\
\hline & & \multicolumn{2}{|c|}{ Intra-day } \\
\hline \multirow{3}{*}{ Conventional } & 15 & $97.56 \pm 2.97$ & $98.22 \pm 3.86$ \\
\hline & 60 & $101.30 \pm 2.12$ & $99.03 \pm 1.88$ \\
\hline & 100 & $100.85 \pm 1.46$ & $101.24 \pm 1.90$ \\
\hline \multirow{3}{*}{ 96-Microwell plate } & 15 & $98.01 \pm 2.15$ & $100.31 \pm 1.91$ \\
\hline & 60 & $101.72 \pm 0.98$ & $100.24 \pm 1.08$ \\
\hline & 100 & $100.10 \pm 0.71$ & $100.36 \pm 0.84$ \\
\hline & & \multicolumn{2}{|c|}{ Inter-day } \\
\hline \multirow{3}{*}{ Conventional } & 15 & $97.25 \pm 3.83$ & $98.35 \pm 3.94$ \\
\hline & 60 & $101.10 \pm 2.14$ & $99.15 \pm 2.31$ \\
\hline & 100 & $101.31 \pm 1.60$ & $100.17 \pm 1.80$ \\
\hline \multirow{3}{*}{ 96-Microwell plate } & 15 & $97.86 \pm 1.87$ & $100.71 \pm 2.08$ \\
\hline & 60 & $101.10 \pm 1.16$ & $100.34 \pm 1.26$ \\
\hline & 100 & $100.81 \pm 0.85$ & $100.15 \pm 0.91$ \\
\hline
\end{tabular}

${ }^{\mathrm{a}}$ Recovery was calculated as the amount found/amount taken $\times 100$. Values are mean \pm RSD for six determinations.

Table 4. Determination of POX in presence of common excipients by the designed microwell spectrophotometric method after fixed time of $10 \mathrm{~min}$.

\begin{tabular}{cc}
\hline Ingredient & Recovery $\left(\% \pm\right.$ SD) $^{\mathrm{a}}$ \\
\hline Starch (50) & $100.51 \pm 2.84$ \\
Glucose (10) & $103.22 \pm 2.65$ \\
Lactose (10) & $102.44 \pm 2.71$ \\
Acacia (10) & $101.92 \pm 2.64$ \\
Magnesium stearate (10) & $98.94 \pm 2.96$ \\
Average \pm SD & $101.41 \pm 1.69$ \\
\hline
\end{tabular}

${ }^{\mathrm{a}}$ Values are mean of three determinations; ${ }^{\mathrm{b}}$ Figures in parenthesis are the amounts in mg added per $20 \mathrm{mg}$ of POX.

concentration of NQS (4.5, 5.0 and $\left.5.5 \times 10^{-2} \mathrm{M}\right)$ and $\mathrm{NaOH}(0.23,0.25$ and $0.27 \mathrm{M})$ reagents, in the reaction temperature $\left(23^{\circ} \mathrm{C}, 25^{\circ} \mathrm{C}\right.$, and $\left.27^{\circ} \mathrm{C}\right)$ or in the reaction time $(9,10,11 \mathrm{~min})$ on the analytical performance of the designed methods. In these experiments, one experimental variable was changed, whereas the others were kept unchanged, and the recovery percentage was calculated each time. It was found that the small change in temperature, reaction time, or the reagents concentrations did not significantly affected the results; where the recovery percentages were $98 \%-102 \% \pm 0.82 \%-2.67 \%$. This provided an indication for the reliability of the proposed methods during routine work.

\subsection{Application of the Designed Methodology to the Analysis of Dosage Forms}

Depending on the obtained validation results, the designed procedures (initial rate or fixed time) were found to 
Table 5. Analysis of POX-containing tablets by the reported and the designed methodology for determination of POX ${ }^{\mathrm{a}}$.

\begin{tabular}{|c|c|c|c|c|c|c|c|}
\hline \multirow{2}{*}{$\begin{array}{l}\text { Spectrophotometric } \\
\text { method }\end{array}$} & \multirow{2}{*}{ Tablet } & \multicolumn{3}{|c|}{ Initial rate method } & \multicolumn{3}{|c|}{ Fixed time method } \\
\hline & & $\begin{array}{l}\text { Label claim } \\
(\% \pm \text { RSD })^{\mathrm{a}}\end{array}$ & t-value ${ }^{\mathrm{b}}$ & F-value ${ }^{b}$ & $\begin{array}{l}\text { Label claim } \\
(\% \pm \text { RSD })^{\mathrm{a}}\end{array}$ & t-value & F-value \\
\hline \multirow{3}{*}{ Conventional } & Trental & $100.96 \pm 1.28$ & 0.09 & 0.72 & $101.60 \pm 2.35$ & 0.04 & 0.35 \\
\hline & Pexal & $100.81 \pm 2.08$ & 0.13 & 0.75 & $100.36 \pm 2.91$ & 0.59 & 0.31 \\
\hline & Vasotal & $97.91 \pm 3.24$ & 0.90 & 0.21 & $99.46 \pm 2.42$ & 0.22 & 0.51 \\
\hline \multirow{3}{*}{ 96-Microwell plate } & Trental & $99.09 \pm 0.67$ & 0.75 & 0.10 & $100.21 \pm 1.36$ & 0.04 & 0.82 \\
\hline & Pexal & $101.92 \pm 1.95$ & 0.08 & 0.85 & $101.51 \pm 1.96$ & 0.10 & 0.59 \\
\hline & Vasotal & $98.62 \pm 1.06$ & 0.59 & 0.28 & $98.40 \pm 1.24$ & 0.70 & 0.46 \\
\hline
\end{tabular}

${ }^{\mathrm{a}}$ The label claim \% for Trental, Pexal and Vasotal tablets determined by the reported method [5] were 98.81 $\pm 1.51,99.46 \pm 1.79$, and 98.1 \pm 1.77 , respectively. Values are mean \pm RSD of six determinations. ${ }^{\mathrm{b}}$ The tabulated values of $\mathrm{t}$ and $\mathrm{F}$ at $95 \%$ confidence limit are 1.81 and 5.05 , respectively.

be suitable for the routine quality control analysis of POX. The concentration of POX was calculated from its corresponding regression equations. The proposed and the reference methods [5] have been tested on commercial tablets. The results obtained by the present methods were statistically compared with those obtained by the reference method with respect to the accuracy and precision. The recovery of the labeled amount was $97.91 \%$ $101.92 \% \pm 0.67 \%-3.24 \%$ (Table 5). The results of $t$ - and F-tests showed that there are no significant differences between the present and reference methods at $95 \%$ confidence level. This proved the applicability of the designed methods for analysis of POX in its pharmaceutical tablets with comparable analytical performance. However, the comparative evaluation and/or recommendations of these methods might be based on the highthroughput value, automation and the precision level of these methods. According to the above consideration, the designed microwell assay might be highly recommended for routine analysis of POX in quality control laboratories.

\section{Conclusion}

The present investigation described the successful use of NQS reagent in the development of simple and rapid spectrophotometric methods for the determination of POX in its tablets. The present methodology was based on the substitution reaction of POX with NQS in alkaline medium. The kinetics of the reaction was determined and both the initial rate and fixed time methods were successfully applied to the determination of POX. The present methodology was carried out in 96-microwell plate as a reaction vessel and compared to the conventional spectrophotometry. The designed method is superior to all the reported conventional spectrophotometric methods for determination of POX in terms of automation and high-throughput. Furthermore, all the analytical reagents are inexpensive, have excellent shelf life, and are available in any analytical laboratory. Therefore, the designed methodology is practical and valuable for routine use as alternative for the existing methods for analysis of POX in quality control laboratories.

\section{Acknowledgements}

The authors thank the Deanship of Scientific Research, Najran University for funding the work; Project Code [nu/mid/14/062].

\section{References}

[1] Sweetman, S (2007) Martindale: The Complete Drug Reference. 35th Edition, Pharmaceutical Press, London, Electronic Version.

[2] Florey, K. (1998) Analytical Profiles of Drug Substances. Academic Press, New York, Vol. 25, p. 245.

[3] Zargari, O. (2008) Pentoxifylline: A Drug with Wide Spectrum Applications in Dermatology. Dermatology Online Journal, 14, 2.

[4] Sastry, C.S.P. and Naidu, P.Y. (1998) Determination of Pentoxifylline in Pharmaceutical Formulations Using Iodine as Oxidizing Agent. Talanta, 46, 1357-1362. http://dx.doi.org/10.1016/S0039-9140(98)00003-4 
[5] Potti, L.R., Doredla, N., Subhani, S. and Kumari, K.N. (2013) UV Spectrophotometric Estimation of Pentoxyphylline In Bulk Drug And Its Pharmaceutical Formulation. International Journal of Pharm Tech Research, 5, 790-799.

[6] El Dawy, M.A., Mabrouk, M.M. and El Barbary, R.A. (2006) Spectrofluorimetric Determination of Drugs Containing Active Methylene Group Using N1-Methyl Nicotinamide Chloride as a Fluorigenic Agent. Chemical \& Pharmaceutical Bulletin, 54, 1026-1029. http://dx.doi.org/10.1248/cpb.54.1026

[7] Chmielewska, A., Konieczna, L., Plenis, A. and Lamparczyk, H. (2006) Quantitative Determination of Pentoxifylline in Human Plasma. Acta Chromatographica, 16, 70-79.

[8] Shehata, M.A.M. and El-Gazayerly, O.N. (2000) Determination of Pentoxifylline in Human Plasma by High Performance Liquid Chromatography with Ultra-Violet Detection. Bulletin of Faculty of Pharmacy, Cairo University, 38, 1-7.

[9] Vlase, L., Kiss, B., Muntean, D. and Leucuţa, S.E. (2010) Rapid High Performance Liquid Chromatography-Tandem Mass Spectrometry Method for Determination of Pentoxifylline and Its Active Metabolites M1 and M5 in Human Plasma and Its Application in Bioavailability Study. Talanta, 82, 945-951. http://dx.doi.org/10.1016/j.talanta.2010.05.064

[10] Korany, M.A., Haggag, R.S., Ragab, M.A.A. and Elmallah, O.A. (2014) Kinetic Investigation of Pentoxifylline Based on Nonparametric Linear Regression of Derivative and Convoluted Derivative Chromatographic and Spectrophotometric Responses. Journal of Liquid Chromatography \& Related Technologies, 37, 475-497. http://dx.doi.org/10.1080/10826076.2012.745151

[11] Lahsini, R. and Monser, L. (2012) Optimization and Validation of a new HPLC Method Using Monolithic Column for Simultaneous Determination of Pentoxifylline and Related Compounds. Pharmaceutical Chemistry Journal, 46, 127-131.

[12] Tsvetkova, B.G., Pencheva, I.P. and Peikov, P.T. (2012) Simultaneous Determination of Pentoxifylline and Its Impurities in Tablet Dosage Forms by RP-HPLC. Der Pharma Chemica, 4, 608-612.

[13] Korany, M.A., Haggag, R.S., Ragab, M.A.A. and Elmallah, O.A. (2013) A Validated Stability Indicating DAD-HPLC Method for Determination of Pentoxifylline in Presence of Its Pharmacopeial Related Substances. Bulletin of Faculty of Pharmacy, Cairo University, 51, 211-219. http://dx.doi.org/10.1016/j.bfopcu.2013.06.001

[14] Sasa, B., Odon, P., Stane, S. and Julijana, K. (2006) Analysis of Surface Properties of Cellulose Ethers and Drug Release from Their Matrix Tablets. European Journal of Pharmaceutical Sciences, 27, 375-383. http://dx.doi.org/10.1016/j.ejps.2005.11.009

[15] Alarfaj, N. and El-Tohamy, M. (2011) New Validated Potentiometric Determination of Vasodilator Pentoxifylline in its Pharmaceutical Formulations and Biological Fluids. Journal of the Chinese Chemical Society, 58, 1-8. http://dx.doi.org/10.1002/jccs.201190099

[16] Crouch, S.R., Cullen, T.F., Scheeline, A. and Kirkor, E.S. (1998) Kinetic Determinations and Some Kinetic Aspects of Analytical Chemistry. Analytical Chemistry, 70, 53R-106R. http://dx.doi.org/10.1021/a1980005s

[17] Kamberi, M. and Tran, T.N. (2012) UV-Visible Spectroscopy as an Alternative to Liquid Chromatography for Determination of Everolimus in a Surfactant Containing Dissolution Media: A Useful Approach Based on Solid-Phase Extraction. Journal of Pharmaceutical and Biomedical Analysis, 70, 94-100. http://dx.doi.org/10.1016/j.jpba.2012.05.038

[18] Martinc, B. and Vovk, T. (2013) A Simple High-Throughput Method for Determination of Antiepileptic Analogues of $\gamma$-Aminobutyric Acid in Pharmaceutical Dosage Forms Using Microplate Fluorescence Reader. Chemical and Pharmaceutical Bulletin, 61, 1009-1014. http://dx.doi.org/10.1248/cpb.c13-00322

[19] Darwish, I.A., Mahmoud, A.M. and Majed, A.R. (2010) A Novel Analytical Approach for Reducing the Consumption of Organic Solvents in the Charge Transfer-Based Spectrophotometric Analysis: Application in the Analysis of Certain Antihypertensive Drugs. Acta Pharmaceutica, 60, 493-501. http://dx.doi.org/10.2478/v10007-010-0035-6

[20] Darwish, I.A., Mahmoud, A.M. and Majed, A.R. (2010) Novel Analytical Approach for Reducing the Consumption of Organic Solvents in the Charge Transfer-Based Spectrophotometric Analysis of Losartan Potassium. International Journal of Research in Pharmaceutical Sciences, 1, 391-395.

[21] Gallo-Martinez, L., Sevillano-Cabeza, A., Campins-Falco, P. and Bosch-Reig, F. (1998) A New Derivatization Procedure for the Determination of Cephalexin with 1,2-Naphthoquinone-4-sulphonate in Pharmaceutical and Urine Samples Using Solid-Phase Extraction Cartridges and UV-Visible Detection. Analytica Chimica Acta, 370, 115-123. http://dx.doi.org/10.1016/S0003-2670(98)00276-1

[22] Mahmoud, A.M., Khalil, N.Y., Darwish, I.A. and Aboul-Fadl, T. (2009) Selective Spectrophotometric and Spectrofluorometric Methods for the Determination of Amantadine Hydrochloride in Capsules and Plasma via Derivatization with 1,2-Naphthoquinone-4-sulphonate. International Journal of Analytical Chemistry, 2009, Article ID: 810104. http://dx.doi.org/10.1155/2009/810104

[23] Wang, H.Y., Xu, L.X., Xiao, Y. and Han, J. (2004) Spectrophotometric Determination of Dapsone in Pharmaceutical Products Using Sodium 1,2-Naphthoquinone-4-sulfonic as the Chromogenic Reagent. Spectrochimica Acta Part A: Molecular and Biomolecular Spectroscopy, 60, 2933-2939. http://dx.doi.org/10.1016/j.saa.2004.02.013 
[24] Darwish, I.A. (2005) Kinetic Spectrophotometric Methods for Determination of Trimetazidine Dihydrochloride. Analytica Chimica Acta, 551, 222-231. http://dx.doi.org/10.1016/j.aca.2005.07.027

[25] Job, P. (1936) Advanced Physicochemical Experiments. Analytical Chemistry, Vol. 16, Second Edition, Oliner and Boyd, Edinburgh, p. 54, 1964.

[26] ICH Guideline (2005) Q2 (R1), Validation of Analytical Procedures: Text and Methodology. London.

[27] Al-Ghannam, S.M., El-Brashy, A.M. and Al-Farhan, B.S. (2002) Fluorimetric Determination of Some Thiol Compounds in Their Dosage Forms. Il Farmaco, 57, 625-629. http://dx.doi.org/10.1016/S0014-827X(02)01223-5

[28] Němocová, I., Čermáková, L. and Gasparič, J. (1996) Spectrophotometric Reactions. Practical Spectroscopy Series, Vol. 22, Marcel Dekker, New York, 198-200.

[29] Pesez, M. and Bartos, J. (1974) Colorimetric and Fluorimetric Analysis of Organic Compounds and Drugs. Marcel Dekker, New York.

[30] Neelgund, G. and Budni, M.L. (2005) Interaction of 2,3-dichloro-1,4-naphthoquinone with $n$-Butylamine in Halocarbon Solvents. Spectrochimica Acta Part A: Molecular and Biomolecular Spectroscopy, 61, 1729-1735. http://dx.doi.org/10.1016/j.saa.2004.07.003

[31] Martin, A.N., Swarbrick, J. and Cammarata, A. (1983) Physical Pharmacy. Third Edition, Lee and Febiger, Philadelphia, 371-374, 344-346.

[32] Ewing, G.W. (1995) Instrumental Methods of Chemical Analysis. 5th Edition, Lippincott-Raven, Philadelphia, 484486. 